compression of the vessels above could be maintained; indeed, the arrest of the circulation to some degree above the aneurismal sac was regarded as essential. In this case, owing to the situation, it was impossible to effect it; nevertheless I thought, under the circumstances of the case, it was warrantable to give galvano-puncturation a trial; and on the 4 th of September, two long, fine needles were introduced an inch within the sac, each being connected with the wires of a galvano-magnetic machine. The object was to avoid shocks, and merely pass a current through the sac. Pressure, as firm as could be borne, was made above, but it was insufficient to stop pulsation in the tumour. The sensible effect produced was, pain in the groin and violent agitation of the whole body. At the expiration of twenty minutes the needles were withdrawn. The tumour was pulsating as before. Strict quietude was enjoined. For three days after neither did the aneurismal tumour nor his general health give indications that any effect had been produced. On the 8 th it is noted, "Tumour painful; is in a nervous and depressed state; cannot sleep." This condition passed off, and nothing presented worthy of notice till the 12th, when pain in the tumour recurred, and he was again in a nervous, restless state. Leeches were applied to the groin, and sedatives administered. As every circumstance in the case, from this date to the termination of it, is interesting, I will give the prominent features from the entries made at the time in the journal.

Sept. 14th.-Much pain last night in the tumour; there is no change in its external appearance, but he thinks himself that it pulsates fainter than it did before. More leeches; anodynes.

15th. - Considerable erysipelatous inflammation on and around the tumour.

16th.-Much constitutional disturbance. Inflammation has spread round the hip; pain of a burning character; thigh much swollen; tumour pulsates. Purgatives and refrigerents ordered.

17th.-Constitutional disturbance abated, and local inflammation subsided.

19th.-Is very uneasy, nervous, restless, and desponding complains of general pains; has lost his appetite, and cannot sleep; circulation quickened. The inflammation is quite gone The tumour appears to be larger, but pulsation not so strong as before. The patient describes an uneasy sensation in the aneurism, which he traces along the course of the vessels to the heart. A bruit is heard in the tumour and along the iliac for an inch or two; heart's impulse aud sounds normal. Digitalis and morphia prescribed.

20th.-Calmer to-day.

21st.-Is returning to the condition he was in previous to the operation.

22nd.-The tumour feels harder, and the pulsation fainter: the heat, he says, is more in the vessel above than in the groin.

27th.-Tumour sensibly harder, and pulsation fainter.

Oct. 6th.-Pulsation to-day is very faint.

8th.-Pulsation hardly to be felt.

11 th.-No pulsation for the last three days; the tumour is hard and diminishing: no pulsation can be heard by the stethoscope for two inches above or below the sac.

20 th. - No return of pulsation, and the tumour is gradually lessening; limb but little longer than the opposite one; has lost the numbness so long felt in it, and only complains of want of power to walk.

It is unnecessary to continue further extracts from the journal. From the date last recorded to the present, Jan. 4th, 1853 , Sergeant $\mathrm{H}$ - has been making good progress in walking.

The remains of the aneurismal sac feels like an enlarged inguinal gland, about the size of a nut. There is odema of the leg still.

In the cases whose treatment by galvano-puncturation led me to try it in Sergeant $\mathbf{H} \longrightarrow$, the cure was effected by a continuous current of electricity, producing coagulation of the blood in the sac. One may infer this, by the rapid effect, from a case of subclavian aneurism: "The tumour was felt to be becoming gradually solidified; and before the withdrawal of the needles, it had become perfectly solid, and pulsation was no longer felt in it." In another case of popliteal aneurism, a like rapid effect was not obtained (attributed to the agitation of the patient); still, in twenty-four hours pulsation ceased, and in seven days he left the hospital, walking quite well. This was not the modus operandi in the Sergeant's case, but inflammation and deposit of lymph, which filled up the sac. This mode is a hazardous one, and was not intentionally induced. The galvanic effect was probably too violent to produce the former, though the machine - an electric magnetic coil one-was used at its lowest power. I thought at first too little had been done; but when I found the external sign of the inflammation going on within the sac, accompanied by much constitutional disturbance, I began to fear that too much had been done. I watched with solicitude or the dark spot on the tumour, the forerunner of sloughing. Happily, the threatened danger passed away. The patient was of sound constitution; he lay in a spacious, well-ventilated ward, and the season was favourable; under opposite circumstances the event might not have been so propitious. Notwithstanding the medical cure effected in this case, I should reluctantly resort to it again for aneurism of the external iliac, unless I had the electric power under command; ${ }^{*}$ but still, a successful case by such means may not be without its value in the records of surgery.

Bellary, Feb. 1853.

\section{CASE OF AN}

OPIUM-EATER AND VEGETARIAN BECOMING BEDRIDDEN.

RECOVERT UPON TAKING ANIMAI FOOD.

By S. L. GIL L, Ese.

ON visiting Mr. C_- I found him to be a little, withered creature, apparently seventy years of age, his real age being only fifty-one; diathesis highly nervous; skin resembling parchment. He had been a vegetarian for five years, and bedridden for seven months, and taken about five grains of solid opium daily for ten years past.

The skin parched; pulse 90 , and very feeble; tongue tremulous, and coated with a brown fur. Bowels acted but one or twice weekly, and then only a very small quantity resembling bird-lime was passed. Urine scanty and highcoloured, but healthy. He had bed-sores upon the nates, sacrum, and scapulæ.

In the first instance I acted slightly upon the liver with mercury-and-chalk, combined with aloes, and brought away some filthy stools; and administered also diffusible stimuli with the tincture of opium, and small quantities of beef-tea; and placed him upon one of Mr. Hooper's water-beds. In a week he had rallied considerably; the bowels acted every second day; tongue clearing at the tip and edges; bed-sores assuming a healthy appearance. At the fortnight's end he took a mild tonic and stimulant, and seemed to relish the beef-tea, but could not bear the sight of meat; took a new-laid egg in chocolate twice daily. At the end of a month, he bore small quantities of mutton, chopped into very fine pieces. The limbs were rubbed daily with and without liniments: this treatment was persevered in for three months. The use of the limbs gradually returned, and he is now walking about collecting his own rents, and takes animal food once daily, and one grain of opium night and morning.

Campbell-terrace, Bow-road, 1853.

\section{REPORT OF AN OPERATION FOR REMOVAI}

\section{OF A TUMOUR FROM A CHILD'S NECK.}

\section{By T. A. BOT'TOMLEY, Esq., M.R.C.S., L.S.A., Huddersfield.}

ANN B-, aged five years, resides about two miles from this town, a good-looking girl, with florid countenance, cheerful, and in excellent health, which she has enjoyed since birth. On November 8,1851 , her parents sought the advice of Mr. Tatham under the following circumstances:-Two years and a half ago, a firm, roundish swelling was for the first time observed on the right side of the neck, immediately below the right angle of the jaw; it was very movable, free from pain, and caused no uneasiness; from that period up to the present time it has gradually increased in size. During its progress, the iodide of potassium has been freely administered internally, and the various preparations of iodine applied externally, but without any benefit. On the right side of the neck, extending obliquely in a line with the sterno-mastoid muscle from the mastoid process, to within an inch of the sterno-clavicular articulation, a tumour presents itself which is over the course of the large vessels, projecting upon the surface of the neck to the size of a man's fist, the external jugular vein with its tributaries being superficial to it. The tumour is oblong in shape, circumscribed, lobulated, and firm; it is situated imme

* A continuous, uninterrupted current is with difficulty obtained from the ordinary coil machine. Would not the hydro-electric chain be wel adapted to the purpose? 
diately beneath the integuments, which are freely movable over it, and appears to be composed of the lymphatic glands of the right side of the neck, hypertrophied to a considerable extent. The upper portion of the tumour is placed below the angle of the jaw and mastoid process, and a line connecting those two points; the middle and lower portions extend forwards and downwards in a line corresponding to the lower part of the larynx and upper three-fourths of the trachea. As far as can be ascertained, the entire mass is freely movable upon the subjacent structures, and free from tenderness. Its dimensions are as follows, - The greatest length taken obliquely over the tumour is six inches and a half; its greatest breadth six inches; and the greatest elevation from the surface of the neck is two and three-quarter inches. An operation for its early removal was recommended, to which the parents of the child readily gave their assent.

Operation, Nov. 26, ten A.M.-Present Dr. Taylor, Messrs. Tatham, Newbould, Rhodes, and Bottomley.-The child being put under the influence of chloroform, was placed on her left side upon a table, with her head hanging over a pillow. Mr. Tatham commenced by making an almost vertical incision, inclining a little backwards from the angle of the jaw over the posterior surface of the tumour, towards and within an inch of the clavicle; a transverse cut was then made from the centre of this incision, including a little upwards and inwards to the anterior middle portion of the tumour, cutting across at almost a right angle the external jugular vein. Mr. Tatham now proceeded to reflect the flaps formed by these incisions from the surface of the tumour, until it was fully exposed; he next dissected the superior posterior part of the tumour from the deep fascia beneath it, gradnally inclining downwards and inwards until he had disengaged about one-half, and reached the middle of the sterno-mastoid muscle. He then commenced with the anterior portion, and dissected carefully upon the tumour until he came down to the carotid sheath, which was inadvertently opened, (by the tumour being dragged backwards, which had a tendency to raise these parts from their normal position,) and the carotid artery with the internal jugular vein were exposed. Mr. Tatham here desisted, and proceeded to dislodge such parts of the tumour as were found to be superficial to the deep fascia. . The operation being so far completed, and the tumour being detached all around, the remaining part of the mass was perceived to dip deep within the anterior superior triangle, interlacing the carotid sheath; the bulk of the tumour was here cut off, and Mr. Tatham was enabled to dissect out more carefully the remaining parts of the morbid mass from the important structures surrounding them.

The removal of the whole mass occupied three-quarters of an hour; no ligature was necessary, although one artery, which appeared to be the nutrient vessel of the tumour, spurted out for a short time, but retracting within its sheath, it soon ceased to bleed. The hremorrhage amounted to six or eight ounces; was principally venous, and speedily checked by the application of cold. The flaps were now brought together and secured by sutures, followed by a few strips of plaister, a small compress, and a roller passed lightly around the neck; she was then placed in bed upon her left side.

On examining the tumour, it was found to be composed of the superficial and deep lymphatic glands of the right side of the neck, varying much in size, one being as large as a hen's egg. They were connected together by condensed areolar tissue. When cut into they presented a pinkish-yellow appearance, and their interior was quite firm.-Half-past Ten P.M Has changed her position frequently since the operation, and now lies on her right side; she is cheerful, and at times talkative; there are some slight febrile symptoms.

Nov. 27 th.-Going on well; slept soundly for several hours during the night; pulse 104, sharp; tongue clean and moist skin hot; slight thirst; bowels operated this morning. Mixture of potassium citratis, one ounce, every three hours.

28th.-Doing well; febrile symptoms abated.

29th.-Neck is swollen, in consequence of which the bandage was slackened; in other respects doing well.

30th.-There has been considerable discharge of seropurulent fluid from the wound during the night; swelling of the neck has disappeared. The wound was dress $d$ to-day, and the sutures removed; edges of wound are adherent, and all appears satisfactory.

Dec. 1st.-O -O wing to there being considerable discharge, the wound was dressed again. During the evening of this day she was dressed, and sat up for a couple of hours.

5th.-On account of pus oozing from the wound to-day when pressure is made above the clavicle, a small compress was applied ; in other respects doing well.
11th.-Since last date there has been a moderate discharge from the part, and at present there is a small swelling, which fluctnates. Linsecd poultice to be applied at night.

15th.-Discharge almost ceased; swelling disappeared. 18th.-Wound entirely cicatrized, and the little girl quite well.

Jan. 12th, 1852.-Up to the present time she has progressed very satisfactorily, and continues perfectly well.

\section{A Aníror \\ OF THE PRACTICE OF}

\section{MEDICINE AND SURGERY IN THE}

HOSPITALS OF LONDON.

Nulla est alia pro certo noscendi via, nisi quam plarimas et morborum, et dissectionum historias, tam aliorum proprias, collectas habere et inter se comparare.-MorgagNI. De Sed. et Caus. Morb., lib.14. Frocmium.

\section{KING'S COLLEGE HOSPITAL}

\author{
Pneumonia; Death; Autopsy.
}

(Under the care of Dr. BoDd.)

Thene are perhaps few affections which have been so thoroughly and successfully studied and investigated as pneumonia; and this inflammation is one of those which, with ordinary practical skill, is easily recognised when it breaks out with a decidedly idiopathic character. But how seldom do we meet with bond fide idiopathic cases! In hospitals, for instance, the number will be found comparatively small, as small, indeed, as idiopathic affections of the heart, - -viz., un. connected with rheumatism, chorea, or pulmonary obstruction.

Pneumonia is, in the cases which came under our cognizance, a kind of extension of bronchitis, or it insidiously invades the lungs during continued or any of the exanthematous fevers. Still it happens here and there that inflammation of the substance of the lung occurs rapidly, and with a very slight amount of premonitory bronchitis, and these cases run a very short and fatal course. The prostration becomes rapidly so great, and the typhoid symptoms so marked, that a doubt may well arise in the mind of the observer, whether the inflammation of the lung be concerned in the generation of the fever, or whether the latter have been the origin and exciting cause of the pulmonary disorganization. This question would now and then deserve a little attention, as the present generation of physicians are perhaps too much inclined to carry to excess the localization of disease. Indeed, some become so absorbed with the morbid changes of organs and to the physical signs to which these changes give rise, that they go on refining the distinctions between these signs, and lose altogether sight of the workings of the system as a whole, and of the effect upon the frame of certain atmospheric, epidemic, or moral influences.

But it is nevertheless true that inflammation of the lung, which rapidly passes into the stage of red hepatization, is a very dangerous affection, and destroys the patient in a short time. Andral puts the average duration of the complaint in this severe form at six days; a great number, however, lasting fifteen and sixteen. The cases which we now beg permission to adduce, and which were recorded by Mr. Hyde, one of Dr. Budd's clinical clerks, offer good illustrations of the occasional rapid progress of the disease; for it ran its course, in the first case, in three or rather eight days, and in the second the poor child died a week after admission, and thirteen days after the beginning of the attack. Nor are these cases easy to treat; for they require antiphlogistics on the one hand, and support on the other, the great difficulty being to balance these two divisions of the treatment in a manner the most conduoive to the patient's safety.

Samuel E- - aged thirty-six years, was admitted May 14 1853, under the care of Dr. Budd. The patient has served the last eight months as porter at dining-rooms, during which time he says that he lived very temperately. The only disturbance to his health has consisted of attacks of ague for three seasons past; he has likewise had some cough, and has spat blood.

The man was taken ill five days before admission, and was much worse on the subsequent day, when he had shivering, pain in the left side, and cough. On that day he took to his 